G. W. Kramer et al. A simple device for the precise addition of liquids

\author{
Header file pcadder.h \\ /* FILE: PGADDER.H \\ Desc: Header file for the slow-adder routines \\ Date: $02 / 12 / 88$ \\ Vers: $1 \cdot 00$ \\ Auth: ARF/JMH \\ $* /$

$\begin{array}{lcc}\text { \#define PRIMMAX } & 40 & \begin{array}{c}/^{*} \text { max. pulses to prime } \\ \text { before returning error }\end{array} \\ \text { \#define PRIMOK } & 5 & \begin{array}{c}\text { /* min. positive readings } \\ \text { to confirm prime*/ }\end{array} \\ \text { \#define PRIMERR } & -1 & \begin{array}{c}\text { / }^{*} \text { error returned if can't } \\ \text { prime*/ }\end{array} \\ \text { \#define PRIMD } & 1000 \begin{array}{c}/^{*} \text { time between prime } \\ \text { pulses (msec.) }\end{array}\end{array}$

\begin{tabular}{|c|c|c|}
\hline \#define ADDOK & 5 & $\begin{array}{l}{ }^{*} \text { min. positive readings } \\
\text { to confirm addn. end } * /\end{array}$ \\
\hline \#define ADDERR & -2 & $\begin{array}{l}/ * \text { error returned on } \\
\text { addition timeout } * /\end{array}$ \\
\hline \#define FLUSHNO & 5 & $\begin{array}{l}/^{*} \text { number of pulses at end } \\
\text { to empty tubing } * /\end{array}$ \\
\hline \#define FLUSHD & 1000 & $\begin{array}{l}/ * \text { time between flush } \\
\text { pulses (msec.) } * /\end{array}$ \\
\hline \#define TIMEMULT & $1 \cdot 25$ & $\begin{array}{l}{ }^{*} \text { maximum addition } \\
\text { time before returning } \\
\text { error is calculated time } \\
{ }^{*} \text { TIMEMULT } * /\end{array}$ \\
\hline \#define MINCALIB & $0 \cdot 001$ & $\begin{array}{l}/ * \text { Sets the minimum drop } \\
\text { size at } 1 \mu \mathrm{l} / \text { pulse } * /\end{array}$ \\
\hline \#define MAXPULSE & 1 & $\begin{array}{l}/{ }^{*} \text { Sets the max pulse rate } \\
\text { to } 1 \text { pulse } / \mathrm{s} * /\end{array}$ \\
\hline
\end{tabular}

\title{
Short courses
}

Loughborough University of Technology, UK, has announced the following short courses for 1989:

Fluorescence and Luminescence Spectrometry - 26-30 June 1989. Fee $£ 480$ including residence and all meals (£450 if paid with booking form). Non-residents $£ 405$ (£375).

Statistics for Analytical Chemistry - 11-14 July 1989. Fee $£ 385$ including residence and all meals ( $£ 355$ if paid with booking form). Non-residents $£ 325$ (£295).

Flow Injection Analysis - 12-14 July 1989. Fee $£ 325$ including residence and all meals ( $£ 300$ if paid with booking form). Non-residents $£ 275$ ( $£ 250$ ).

For further details please contact: Mrs J. E. Stirling, Department of Chemistry, Loughborough University of Technology, Loughborough, Leics. LE11 3TU. Telephone: (0509) 222549 .

HPLC Technology and Applied Ghromatography Systems are holding five HPLC Beginners Training Courses during 1989. Each course will last three days and will include both practical and discussion sessions. The courses are held at The Deanwater Hotel, Woodford, Cheshire. All purchasers of HPLC Systems from ACS receive a complimentary place on the course.
For further information please contact: Applied Chromatography Systems, The Arsenal, Heapy Street, Macclesfield, Cheshire SK11 7JB. Telephone: (0625) 34575.

Chemserve have announced two courses for 1989:

Fluorine Spectroscopy Workshop - 10-11 April 1989.

Mass Spectrometry for Beginners - 17-18 April 1989.

For further information, please contact: Chemserve, UMIST, PO Box 88, Manchester M60 1QD. Telephone: 0612287700.

The University of Liverpool is holding a short course on Modern Spectroscopic Techniques, 2-7 April 1989.

For further information, please contact: $\operatorname{Dr} A$. Hodgson, Dept. of Chemistry, University of Liverpool, PO Box 147, Liverpool L69 $3 B X$.

Royal Society of Chemistry Residential School - 28-31 March 1989. Computer Methods in UV, vis and ir Spectroscopy, Polytechnic of Wales.

For further information, contact Ms L. Hart, RSC, 30 Russell Square, London WC1B 5DT. Telephone: 01-631-1355. 


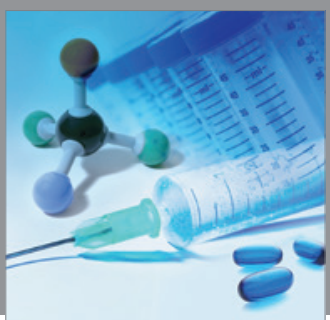

International Journal of

Medicinal Chemistry

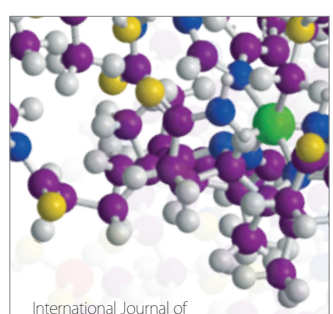

Carbohydrate Chemistry

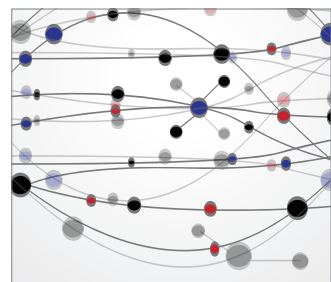

The Scientific World Journal
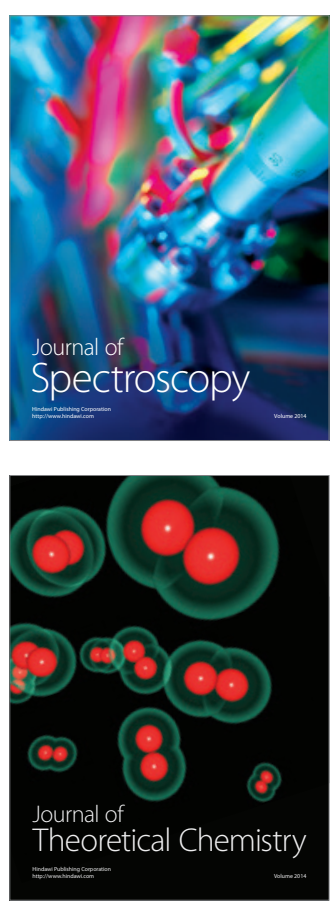
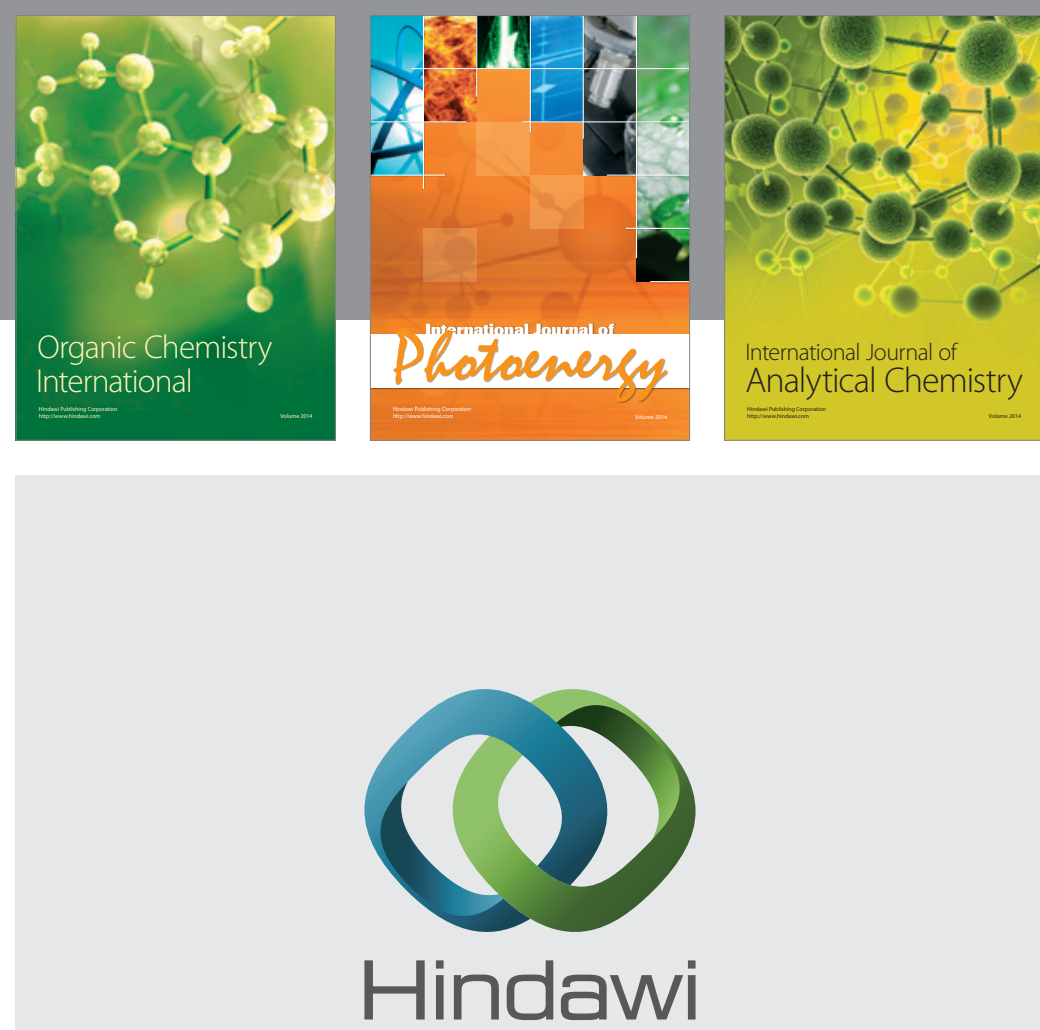

Submit your manuscripts at

http://www.hindawi.com
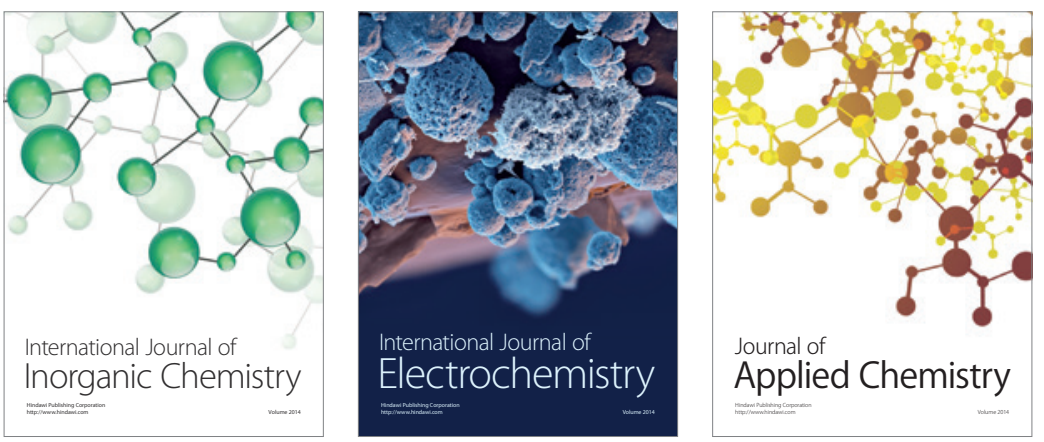

Journal of

Applied Chemistry
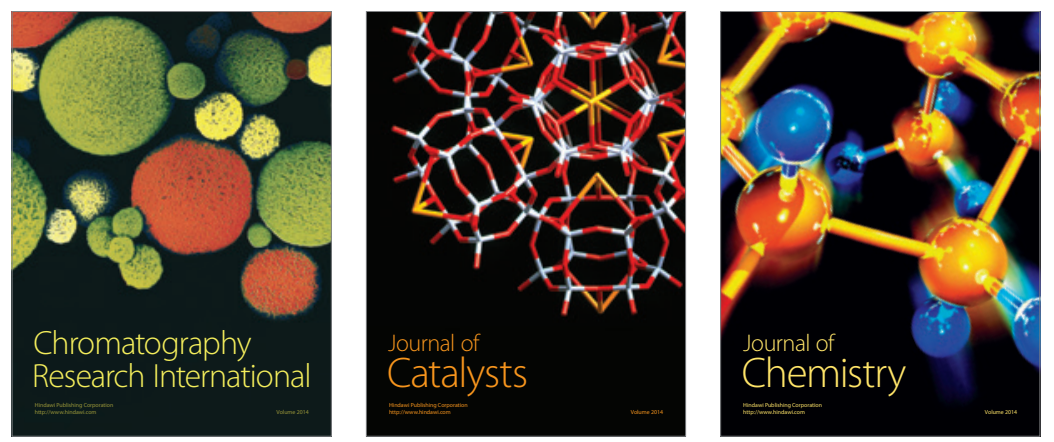
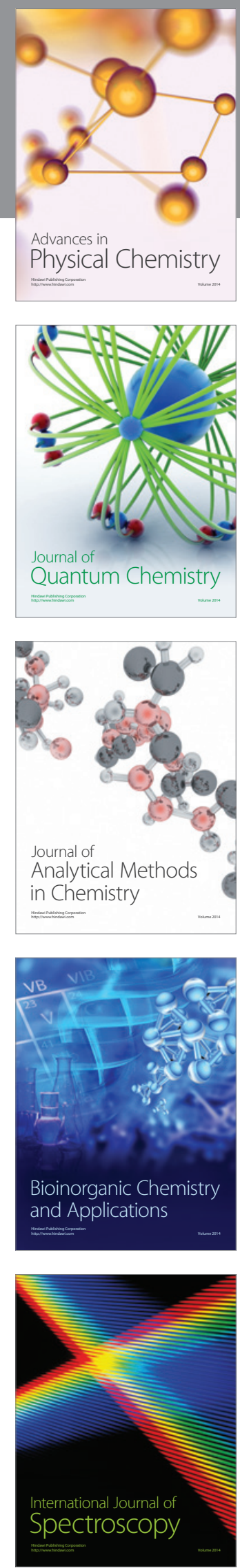